\title{
Agente tutor modelado com arquitetura BDI
}

\author{
Alexandre Gaspary Haupt, Doutorando no PPGEE da UFRGS - ahaupt@ senairs.org.br \\ Maria Lucia Pozzatti Flores, Doutorando no PGIE da UFRGS - mlflores@ terra.com.br \\ Mariane Kneipp Giareta, Doutorando no PGIE da UFRGS - mariane@upf.br \\ Sérgio Helegda, Doutorando no PPGEE da UFRGS - shelegda@ gmail.com \\ Cláudio Rodrigues Cunha, Doutorando no PGIE da UFRGS - cunha@uergs.edu.br \\ Thiago Viaro, Doutorando do PPGC da UFGRS - tviaro@gmail.com \\ Thiago Paim, Doutorando do PPGC da UFGRS - thiagopaim@gmail.com \\ Rosa Maria Viccari, Professora Dr ${ }^{\mathrm{a}}$. do PPGC da UFGRS - rosa@inf.ufrgs.br
}

\section{Resumo}

A proposta desse trabalho é apresentar o desenvolvimento de um aplicativo em software que utiliza a interação de dois tipos de agentes: um cognitivo e outro reativo. $\mathrm{O}$ agente cognitivo é representado pelo usuário, neste caso um motorista de táxi, que executa ações sobre um cenário de acordo com diferentes situações apresentadas. $\mathrm{O}$ agente reativo recebe informações do ambiente e interage com o motorista através de dicas que podem ser expressas através de sinalização e avisos sonoros. Os planos são descritos por um conjunto de regras que interagem com a base de conhecimentos e com as informações recebidas. Neste artigo é apresentada uma aplicação prática obtida na modelagem de um agente que contribuirá para o desenvolvimento de instrumentos de aprendizagem num sistema para orientar um motorista de táxi.

Palavras chave: Inteligência Artificial; BDI; Sistemas Tutores Inteligentes.

\begin{abstract}
The propose of this work is to show the development of an application in software that uses the interation of two types of agents: a cognitive one and other reagent. The cognitive agent is represented by the user, in this case a taxi driver, that executes actions on a scenery in agreement with different presented situations. The agent reagent receives information of the environment and it interacts with the driver through clues that can be expressed through signaling and resonant warnings. The plans are described by a group of rules that interact with the base of knowledge and with information of the environment. In this article, a practical application obtained from an agent's modeling, which will help the development of learning instruments in a system created to guide a taxi.
\end{abstract}

Keywords: Artificial Intelligence; BDI; Intelligent Tutor Systems.

\section{1- INTRODUÇÃO}

A Inteligência Artificial (IA) tem despertado grande interesse da comunidade científica. Muitos problemas, que seriam solucionados trivialmente pela mente humana, constituem-se num grande desafio para os pesquisadores dessa área. Os computadores poderiam raciocinar de forma análoga aos seres humanos? As máquinas seriam capazes de resolver tais problemas em tempo hábil e de maneira satisfatória?

As inferências apresentadas neste trabalho foram baseadas nas principais idéias encontradas em um artigo de Michael E. Bratman (1988). Segundo esse autor, constatase a crescente vontade em construir máquinas que se comportem racionalmente.

(Giraffa, 1999) afirma que o desenvolvimento da IA permitiu a constituição das bases utilizadas para compor uma ciência da mente. A partir do estudo da IA, os cientistas refletem sobre o significado do que é "ser inteligente", ter vida mental, ter consciência e outros conceitos empregados nas áreas afins. 
Entre as arquiteturas de estados mentais está a arquitetura conhecida como BDI (Beliefs - crenças; Desires - desejos; Intentions - intenções). Segundo (Giraffa, 1999), as idéias básicas da abordagem BDI são: descrever o processo interno de um agente utilizando o conjunto daqueles estados mentais e definir uma arquitetura de controle através da qual o agente possa selecionar o curso de suas ações.

Algumas abordagens de arquitetura BDI agregam as noções de planos e objetivos. (Weiss, 1999) afirma que "planos" seria "o conjunto de sub-tarefas que deve ser seguido, quando gerada uma intenção, para a realização de uma tarefa sobre o ambiente".

(Bratman, 1988) diz que as soluções em IA para o problema do planejamento consistem, geralmente, de métodos de busca no espaço de possíveis ações para computar alguma seqüência que irá resultar em um objetivo particular, ou em um conjunto de objetivos. Um agente racional deve desenvolver o raciocínio "meio-fim" e "pesar" as alternativas competitivas no curso de sua ação.

Uma arquitetura adequada de um agente de IA deve incluir a capacidade para ambas as características, assim como o desenho de tal arquitetura deve especificar como estas capacidades interagem. Ainda, tudo deve ser feito considerando que agentes, sejam humanos ou robôs, têm recursos limitados, isto é, os agentes não são capazes de processamento ilimitado em um intervalo finito de tempo. Cada agente possui um conjunto finito de capacidades específicas e objetivos próprios em relação aos estados do ambiente que quer atingir, mecanismos para a interação e coordenação dessas entidades são necessários, pois, em geral, os agentes não conseguem atingir todos os seus objetivos isoladamente.

\section{REVISÃO BIBLIOGRÁFICA}

Segundo (Russel, 1995), um agente é uma entidade que pode perceber seu ambiente através de sensores e atuar sobre ele através de atuadores. Um agente humano tem olhos, ouvidos e outros órgãos sensores, já as mãos, pernas e boca, por exemplo, funcionam como atuadores. Um agente robótico utiliza microfones, sensores infravermelho, sensores de temperatura para captar informações do ambiente. Os motores, solenóides e sistemas eletropneumáticos constituem-se de mecanismos que atuam no ambiente.

Um outro conceito é que um agente racional é aquele que faz as coisas certas, mas existe a necessidade de definir quais são as coisas certas. Para avaliar o seu desempenho, deve considerar quais sensores e atuadores são importantes para o processo. Não se pode culpar um agente por não ter feito aquilo que ele não pode perceber ou por não ter atuado de uma maneira que não era capaz de fazer.

Um agente racional ideal deve considerar o tempo para a execução da tarefa. Para cada seqüência de percepção um agente racional ideal deve atuar de maneira a maximizar sua medida de desempenho com base na evidência fornecida pela seqüência percebida e no conhecimento que tenha adquirido previamente.

O trabalho da IA é projetar o programa do agente, ou seja, uma função que implemente o mapeamento que vai de seus sensores a seus atuadores. O programa deverá atuar em uma máquina (e esse procedimento é chamado de "arquitetura"). $\mathrm{O}$ programa e a arquitetura formam, em linhas gerais, o agente.

De acordo com (Pereira, 1997), incorporarem agentes dentro de software de educação proporciona uma melhora substancial nos aspectos pedagógicos destes ambientes, pois eles possibilitam interações naturais mais intensas por intermédio da aproximação entre estudantes e sistema. Esses agentes são denominados de "agentes pedagógicos". 
Os agentes pedagógicos são, segundo (Giraffa, 1999), aqueles utilizados em sistemas que utilizam o paradigma de agentes desenvolvidos para fins educacionais, podendo atuar como tutores virtuais, estudantes virtuais, ou ainda companheiros virtuais de aprendizagem, tendo como objetivo auxiliar os estudantes no processo de ensino e aprendizagem.

Um agente pode ser racional se ele realizar o raciocínio meio-fim, isto é, se o agente pesar as alternativas competitivas no curso de sua ação. Uma arquitetura adequada de um agente de IA além de levar em conta tais características, deve especificar como estas capacidades interagem.

(Bratman, 1988) estudou quatro funções: o raciocínio meio-fim, o analisador de oportunidades, o filtro de processo e o processo deliberação. Essas funções constituemse num sistema de raciocínio prático, isto é, um sistema no qual um agente pode formar, completar, revisar e executar planos.

Um plano de um agente torna o raciocínio prático mais tratável de duas formas:

- Como entrada de raciocínio meio-fim: eles fornecem um resultado concreto e limpo para raciocinar.

- Como entradas para processo de filtragem: eles estreitam o leque de deliberação para um limitado conjunto de opções.

As regras que um plano de agente deve seguir são: devem impulsionar o raciocínio meio-fim; devem provar restrições em quais opções necessitam ser seriamente consideradas e. ainda, devem influenciar as crenças, nas quais o raciocínio prático adicional será baseado.

O mesmo autor afirma que a motivação de um agente com arquitetura BDI é o "raciocínio prático". Neste caso o raciocínio prático é o processo de decidir, a cada momento, que ações tomar para chegar mais perto dos objetivos. Isto implica em decidir quais objetivos que o agente quer realizar e de que modo vão ser executados esses objetivos.

O agente requer três conjuntos de sentenças lógicas, os quais são baseados em estados mentais citados anteriormente. Estes estados mentais são consistentes entre si e seu componente filosófico é baseado em uma teoria de ações racionais dos seres humanos.

As crenças simbolizam visões importantes que o agente possui em relação ao seu ambiente. Ele pode ter crenças sobre o mundo, sobre outros agentes, sobre interações sobre outros agentes e também pode ter crenças sobre suas crenças. Estas crenças podem ser até contraditórias entre si. O agente as utiliza para simbolizar suas expectativas sobre possíveis estados futuros e podem atuar como um componente informativo dos estados do sistema, isto é, o possível conhecimento do agente de forma explícita.

O modelo de crenças consiste de um ou mais estados de crenças que pode ser definido e usado para especificar o estado inicial do agente, armazenando informações do agente sobre o ambiente, seu estado interno e as ações que pode executar.

Os desejos são os estados do mundo que o agente quer atingir. Especificam as preferências ou estados desejáveis que o agente poderia alcançar. Estas preferências podem ser consistentes ou inconsistentes. Por exemplo: Eu desejo perder $30 \mathrm{~kg}$, mas gostaria de continuar comendo quilos de chocolate. É um desejo inconsistente, pois de acordo com as regras existentes, o agente não conseguirá atingi-lo.

Os desejos servem como motivadores para que o agente possa vir a realizar metas na busca de alcançar (satisfazer) o seu desejo. Os objetivos são subconjuntos consistentes dos desejos. 
As intenções são comprometimentos com ações para alcançar o objetivo. Para realizar suas metas executam planos. As metas são realizadas a partir de intenções causadas pelos desejos.

No exemplo citado anteriormente, a motivação era "Eu desejo perder $30 \mathrm{~kg}$ ". Que ações eu devo tomar para atingir tal desejo? Algumas ações que poderíamos realizar a partir da decisão tomada para "emagrecer": (a) Não comerei mais doces e chocolates; (b) Não jantarei após as 21horas; (c) Farei uma hora de academia; (d) Eliminarei as frituras e gorduras das minhas refeições. Estas ações, seguidas à risca, levariam-me, em um determinado tempo, a concretizar meu desejo. Logo, estou me comprometendo em realizar diariamente tais ações na busca de atingir o desejo inicial. Neste momento, tenho uma intenção. Note que as intenções determinam o processo de raciocínio prático uma vez que elas determinam as ações a serem realizadas; enquanto se tem uma intenção particular haverá consideração por ações que são consistentes com relação aos desejos e crenças para realização desta intenção. A escolha das opções deve ser feita com cuidado para não surgirem sub-intenções inconsistentes.

As intenções devem ser persistentes. Mas, quando elas forem muito persistentes fazem o agente perder tempo. Já quando forem pouco persistentes, elas não alcançam nenhum objetivo. É necessário avaliar (reconsiderar) as intenções com alguma frequiência. O agente deve estar sempre perguntando: ainda é possível realizá-las? Já foram realizadas? Seria melhor se comprometer com outra intenção? Essa reconsideração das intenções é um dilema na arquitetura BDI, pois se o agente não pára para reconsiderar suas intenções, ele pode perder tempo tentando o impossível. Se o agente para demais para reconsiderar, ele não tem tempo de fazer mais nada. $\mathrm{O}$ fundamental é encontrar o equilíbrio.

\subsection{Plano de agente}

Um plano de agente, para (Bratman, 1988) é uma descrição de regras funcionais que torna o raciocínio prático mais tratável, tanto na entrada para o "raciocínio meiofim", onde fornecem um resultado concreto para raciocinar, quanto nas entradas para o processo de filtragem, onde estreitam o leque de deliberação para um limitado conjunto de opções. Os planos de agente possuem a função restritiva, isto significa que as opções que são inconsistentes com os planos existentes devem ser filtradas ou retiradas.

Um plano deve ser relativamente estável e ainda resistente a reconsiderações e abandonos. Os planos devem ser consistentes internamente com as crenças do agente e apresentar coerência de meios-fins. Cada um deles deve ser preenchido com sub-planos concernentes a meios, passos iniciais e cursos de ações relativamente específicos.

Para (Giraffa, 1999), intenções e planos desempenham dois papéis diretos como entradas para o raciocínio prático. Primeiro as intenções prévias freqüentemente colocam decisões para deliberação futura ao se considerar a necessidade de coerência de meios-fins. $\mathrm{O}$ agente necessita preencher o seu plano o mais cedo possível com as especificações para poder executá-lo. Dada a necessidade entre a consistência interna e as crenças, as intenções prévias restringem futuras intenções. Essas intenções prévias colocam problemas para deliberação, estabelecendo padrões de relevância para as opções em consideração. Além disso, restringem as soluções para esses problemas providenciando um filtro de admissibilidade para as opções. Dessa forma, as intenções prévias e os planos ajudam a tornar o processo de deliberação tratável por agentes com substancial limitação de recursos.

\subsection{A arquitetura BDI}

De acordo com (Bratman, 1988), o comportamento de um agente com arquitetura BDI se faz da seguinte maneira: a função de revisão de crenças (FRC) recebe a 
informação sensória (percebe propriedades do ambiente) e, consultando as crenças anteriores do agente, atualiza essas crenças para que elas reflitam o novo estado do ambiente. Com essa nova representação do estado do ambiente, é possível que novas opções, de estados a serem atingidos, fiquem disponíveis. A arquitetura é mostrada na figura 1.

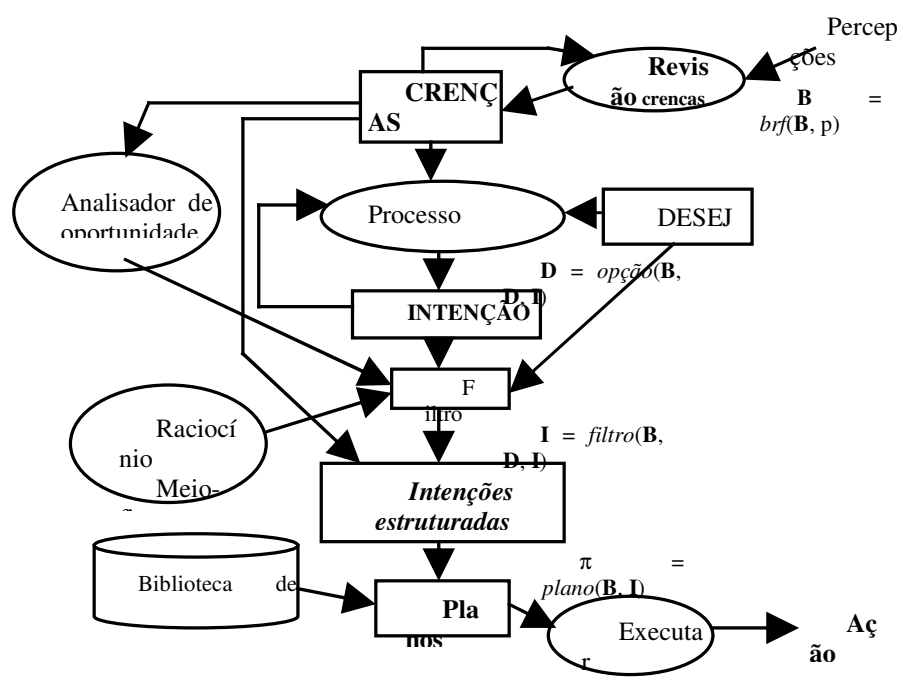

Figura 1 - Arquitetura BDI (Florea, 2005)

A função geradora de opções verifica quais as novas alternativas de estados a serem atingidos, que são relevantes para os interesses particulares daquele agente. Isto deve ser feito com base no estado atual do mundo (conforme as crenças do agente) e nas intenções com que o agente já está comprometido. A atualização dos objetivos se dá, então, de duas formas: as observações do ambiente possivelmente determinam novos objetivos do agente, e a execução de intenções de mais alto nível pode gerar a necessidade de que objetivos mais específicos sejam atingidos.

(Giraffa, 1999) diz que uma vez atualizado o conhecimento e a motivação do agente, é preciso, em seguida, decidir que curso de ações específico será usado para alcançar os objetivos atuais do agente (para isso é preciso levar em conta os outros cursos de ações com os quais o agente já se comprometeu, para evitar ações incoerentes, bem como eliminar intenções que já foram atingidas ou que se tornaram impossíveis de ser atingidas). Esse é o papel da "função filtro", que atualiza o conjunto de intenções do agente, com base nas crenças e desejos atualizados e nas intenções já existentes. Esse processo realizado pela função filtro para determinar como atualizar o conjunto de intenções do agente é normalmente chamado de "deliberação".

Com o conjunto de intenções já atualizado, a escolha de qual ação específica, entre aquelas pretendidas, será a próxima a ser realizada pelo agente no ambiente. Esse processo é realizado pela função "ação". Em certos casos, em que não é necessária a priorização entre múltiplas intenções, a escolha pode ser simples. Basta escolher qualquer uma entre as intenções ativas, desde que se garanta que todas as intenções terão, em algum momento, a oportunidade de serem escolhidas para execução.

No processo de desenvolvimento devemos analisar os diferentes planos para encontrar os objetivos do agente seguindo os passos: para cada objetivo, analisar os diferentes contextos nos quais os objetivos têm que serem encontrados; para cada um destes contextos, decompõem os objetivos em atividades representados por subobjetivos e ações; para cada objetivo, analisar em que ordem e sobre que condições 
essas atividades e ações necessitam ser executadas, como falhas devem ser conduzidas e gerar um plano para encontrar o objetivo.

(Bratman, 1988) sugere que as crenças do sistema são construídas seguindo os seguintes passos: analisar os vários contextos e condições que controlam a execução das atividades e das ações; analisar os dados de entrada e saída requeridos para cada subobjetivo do plano e assegurar que essa informação seja disponível tanto como crença ou como saída de sub-objetivos anteriores no plano.

O problema no desenvolvimento do raciocínio prático do agente é como alcançar um equilíbrio entre esses diferentes conceitos, principalmente no que se refere a abandonar intenções. Às vezes é necessário que um agente deixe de considerar uma intenção, porém as reconsiderações têm um custo computacional. Uma possível sugestão seria o agente determinar uma intenção, cumprir todas as tarefas relacionadas a ela e, depois, determinar outra intenção.

\subsection{A função filtro}

O processo de filtragem se dá por duas maneiras: por compatibilidade e pelo mecanismo do filtro overriding que é um processo de escalonamento das opções, uma vez que o número de opções pode superar o número esperado. Os dois mecanismos de filtro trabalham em paralelo.

Para (Bratman, 1988) a função filtro faz o agente reconsiderar os planos quando o raciocínio prático for incompleto, isto é, quando os planos forem limitados de recursos e de conhecimento. A função filtro obtém ações a serem tomadas de acordo com os novos problemas existentes no ambiente ou, ainda, com as novas oportunidades no ambiente. Os planos são reavaliados quando os planos existentes são suspensos, sendo reavaliados com as novas intenções. Em paralelo ao filtro de compatibilidade, os planos incompatíveis podem vir a ser executados ou quando forem melhores que os atuais, ou quando forem coerentes aos desejos e às crenças do agente.

A sensibilidade é um fator importante para o filtro e por isto deve ser bem planejada: se o filtro for muito sensível irá reconsiderar todos os planos a cada evento novo deixando de executar mais ações. Se for pouco sensível perderá oportunidades e não reagirá a variações significantes. No processo de deliberação são avaliados quais planos deverão ser executados. Mesmo planos incompatíveis são analisados, quando indicados, pela função filtro. Os planos indicados pela função filtro e compatíveis com os planos existentes são encaminhados para o processo de decisão. Só haverá mudança de planos se houver benefícios nesta troca, pois a troca de planos demanda esforço e mantém o agente "ocioso".

\section{MATERIAIS E MÉTODOS}

No contexto apresentado, buscamos elaborar uma aplicação prática que possa vir a ser utilizada numa situação de ensino-aprendizagem, desenvolvendo um sistema para orientar um motorista na condução de seu veículo. O veículo trafega em um ambiente limitado sujeito às situações previstas, mas inesperadas. Neste sistema temos dois agentes, o agente humano (o motorista) e o agente tutor que está sendo proposto. Os agentes interagem entre si de modo que apenas o agente humano executa a ação, enquanto o agente tutor sugere alternativas de ações com vistas a atingir o objetivo da melhor forma.

O agente tutor pode ser implementado usando a ferramenta CBUILDER. Tratase de uma ferramenta para programação visual, em linguagem $\mathrm{C}$, orientada a objeto. Sua estrutura é executada sobre a plataforma WINDOWS a qual permite utilizar bibliotecas desenvolvidas para modelar a arquitetura BDI. 
$\mathrm{Na}$ linguagem $\mathrm{C}$, os planos, desejos e crenças são descritos em um arquivo utilizado para representá-los. Os dados contidos nesses arquivos são acessados pelo aplicativo em linguagem $\mathrm{C}$ periodicamente e indicam o estado do sistema.

Nesta proposta o agente tutor orienta um motorista de táxi conduzir seu veículo. O cenário proposto para o motorista de táxi e o tutor assistente foi desenvolvido em um ambiente limitado que representa um bairro de uma grande cidade. As ruas ortogonais, dispostas de maneira simétrica, onde cada quadra apresenta um conjunto simbólico de casas. Nesse cenário estão dispostos diferentes ícones que podem interagir com os agentes através de ações consideradas inesperadas, como: pedestres e veículos, que transitam de forma aleatória, ou ainda sinaleiras, que controlam o fluxo dos veículos. De forma a contribuir para um ambiente mais adverso, também foram acrescentadas algumas situações bastante comuns no cotidiano de um motorista: furo do pneu e término do combustível. Essas são situações previstas, contudo inesperadas, por isso uma variável randômica é utilizada no controle de seus estados.

O objetivo do agente cognitivo é levar um passageiro de um local para outro dentro de um intervalo de tempo determinado. Nesse aplicativo, o usuário tem controle de três diferentes ferramentas para interagir com o ambiente: a direção, a troca do pneu e o abastecimento de combustível. Apesar do usuário possuir um conjunto de ações limitadas, o cenário escolhido impõe um conjunto de regras de trânsito real que tornam, em seu contexto, a forma de agir bastante complexa. Assim o motorista se confronta com obstáculos, como transeuntes, veículos e sinaleiras, que devem ser respeitados para completar seu objetivo. Quando o passageiro chega ao destino dentro do intervalo de tempo determinado, são creditados bônus ao usuário. Caso alguma regra de trânsito não seja respeitada durante o trajeto ou o passageiro chegue atrasado, o usuário pagará uma multa pela infração cometida, significando perda de créditos.

A arquitetura de um agente racional deve permitir raciocínio meio-fim e levar em conta a limitação de recursos, pesando alternativas competitivas. No ambiente proposto, um dos papéis do agente tutor é limitar a quantidade de raciocínios práticos necessários. Isto é proporcionado pela filtragem proposta na arquitetura BDI que monitora, constantemente, o processo. Isso possibilita minimizar a freqüência em que o agente permanece em situações desfavoráveis.

Busca-se um mecanismo que seja capaz de ser alterado pelo próprio agente caso ele perceba que está empregando tempo demais em deliberações infrutíferas. O agente é "cauteloso" quando, após uma opção incompatível dispara a ação de um filtro que possa indicar uma intenção específica. Quando uma opção incompatível é proposta e falha em disparar o gatilho do respectivo filtro, o agente está sendo "audacioso". Para um agente bem projetado, o mecanismo de filtragem que decide não deverá ser nem demasiadamente cauteloso, nem audacioso.

Considerando-se possíveis situações de conflito defrontadas por um agente assistente para motorista de táxi, são apresentados os cenários abaixo. O tutor assistente pode fazer algumas considerações, chamadas meio-fim, antes de chegar com um passageiro ao destino. Ele decide a melhor forma de resolver um problema para chegar ao local desejado, baseado na crença de que existe combustível suficiente e tempo hábil para percorrer o trajeto.

Cenário 01: O agente é confrontado com a sinaleira fechada, porém mesmo seguindo a sinalização, existe tempo suficiente para chegar ao destino dentro do tempo determinado. $\mathrm{O}$ analisador de oportunidades propõe a opção: parar o carro e aguardar o sinal verde. Essa opção é compatível com a intenção do agente tutor de resolver o problema dentro do prazo de tempo determinado, por isso ele reconsidera o seu plano considerando suas crenças. Nesse cenário o agente é considerado cauteloso. 
Cenário 02: $\mathrm{O}$ agente é confrontado com a sinaleira fechada, porém constata que se seguir à sinalização de trânsito não haverá tempo suficiente para chegar ao destino dentro do tempo determinado. $\mathrm{O}$ analisador de oportunidades propõe uma nova opção: parar o carro e aguardar o sinal verde, somente se houver obstáculos na frente do carro. Essa opção é incompatível com a intenção do agente tutor de resolver o problema dentro de um prazo de tempo determinado, mas ele reconsidera o seu plano por que seu mecanismo de filtragem é acionado. Sua deliberação modificou o plano inicial considerando suas crenças. Nesse cenário, mesmo com o sinal vermelho acionado, se não houver obstáculos, o agente tutor irá sugerir para o motorista avançar o sinal, sendo por isso considerado audacioso.

Cenário 03: O agente é confrontado com a situação em que o nível de combustível é insuficiente para alcançar o destino. $\mathrm{O}$ analisador de oportunidades propõe uma nova opção: abandonar a trajetória de destino e sugerir que o motorista se dirija para o posto de abastecimento mais próximo. Nesse cenário, o agente tutor considera os prós e os contras e sugerirá para o motorista uma nova trajetória, sendo por isso considerado cauteloso.

Cenário 04: O agente pode se confrontar ainda com a situação em que um pneu do táxi esvazie e seja custoso alcançar seu destino com o mesmo furado. Nesse caso, o analisador de oportunidades propõe a opção de parar o carro para efetuar a troca do pneu antes de continuar a trajetória. Essa opção é incompatível com a intenção do agente tutor de resolver o problema, por isso ele reconsidera o seu plano inicial. Nesse cenário o agente é considerado cauteloso, mesmo que todas as soluções propostas apontem para uma única alternativa: mesmo em casos de tempo insuficiente, sinal fechado ou obstáculo no caminho, o reparo é essencial para atingir o objetivo final.

Considerando o grande número de possibilidades existentes, poderá haver casos em que a estratégia colocará o agente tutor em situações nas quais sua cautela não valerá a pena. Entretanto, feitas as considerações existentes, a estratégia final será a mais adequada. Um filtro mais finamente sintonizado ajudaria no sentido de evitar situações indesejadas, como: correr mais riscos para chegar ao destino, terminando sem combustível ou atropelando um pedestre, por exemplo.

Nesses casos, ao mesmo tempo em que, evitam-se cautelas que não valham a pena, corremos um risco maior de audácia que também não vale a pena. O oposto também é verdadeiro, ou seja, enquanto tenta-se evitar cautelas desnecessárias, como parar veículo mesmo quando as pessoas estão a uma distância segura. Nesses casos corremos o risco de aumentar cuidados indesejáveis não solucionando o problema.

Os sensores servem para monitorar o estado do ambiente. No sistema tutor proposto tem-se sensores com faixa de valores discretos e outros com valores booleanos, conforme relacionado na tabela 1. Esses dados irão interagir com a base de conhecimentos formada pelas crenças e desejos, que geram intenções, e que poderão se tornar ações.

Tabela 1 - Sensores e tipos de variáveis

\begin{tabular}{cc}
\hline Sensor & Faixa de Valores \\
\hline Marcador de velocidade & Discreto \\
Marcador de nível de combustível & Discreto \\
Marcador de tempo restante & Discreto \\
Pneu furado & Booleano \\
Sinaleira fechada & Booleano \\
Faixa de pedestre & Booleano \\
\hline Obstáculos & Booleano \\
\hline & \\
\hline
\end{tabular}


A Figura 2 mostra o sistema tutor proposto, explicitando os níveis entre as plataformas utilizadas, sensores e atuadores.

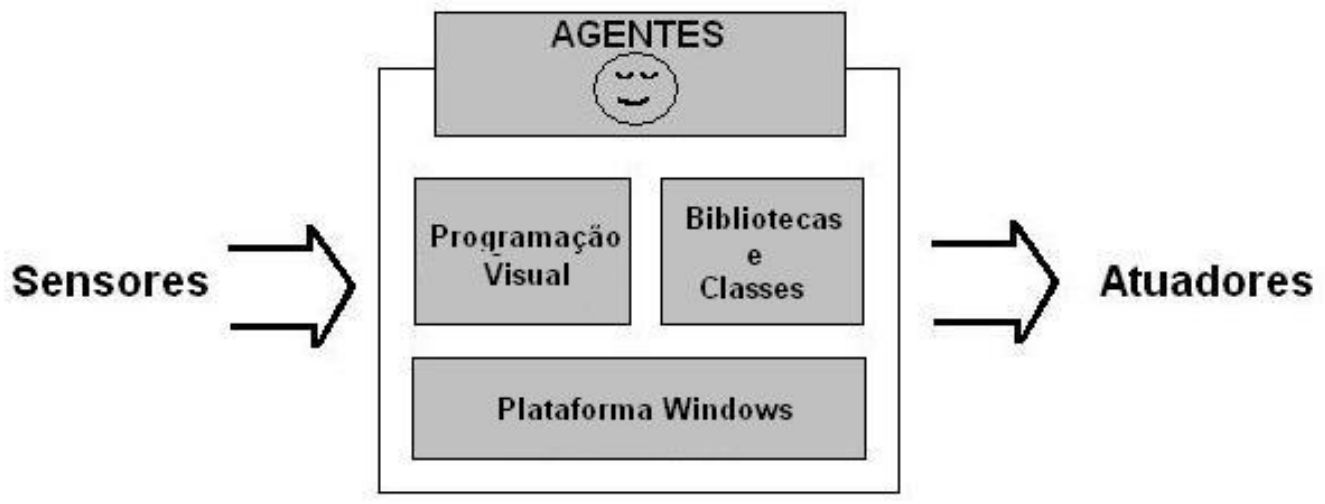

Figura 2-Arquitetura proposta para o Sistemas Tutor Assistente de motorista

A Tabela 2 mostra a base de conhecimentos, formada por crenças e desejos, utilizada pelo sistema tutor proposto.

Tabela 2 - Base de conhecimento

\begin{tabular}{|c|c|}
\hline \multicolumn{2}{|c|}{ Base de Conhecimentos } \\
\hline Crenças & Desejos \\
\hline Tem combustível suficiente para chegar ao destino. & Chegar ao destino em tempo menor ou igual à 30min. \\
\hline $\begin{array}{l}\text { A prioridade é a segurança dos humanos (não pode } \\
\text { atropelar pedestres). }\end{array}$ & $\begin{array}{l}\text { Levar passageiro ao destino com o maior número de } \\
\text { créditos possível. }\end{array}$ \\
\hline Trafega apenas no limite de velocidade permitido. & Não cometer infrações. \\
\hline Pode chegar ao destino em tempo menor que 30 minutos. & Não rodar sem passageiros. \\
\hline Não pode colidir em outros objetos. & Não atropelar pedestres. \\
\hline Precisa pagar combustível, consertos e multas impostas. & -- \\
\hline Conhece a trajetória para chegar ao destino. & -- \\
\hline Conhece a localização do posto de abastecimento. & -- \\
\hline Tem passageiro esperando para transportar. & -- \\
\hline
\end{tabular}

O raciocínio, formado por regras de inferência SE-ENTÃO é mostrado na Tabela 3. Os planos são sugeridos ao motorista através de mensagens, informadas por um display instalado no painel do carro e por avisos sonoros.

Tabela 3 - Regras e Planos

\begin{tabular}{ll}
\hline \multicolumn{1}{c}{ Regras (se) } & \multicolumn{1}{c}{ Planos (então) } \\
\hline Se furar o pneu & Tutor sugere parar o táxi, e; \\
Se trocar o pneu & $\begin{array}{l}\text { Tutor sugere troca do pneu } \\
\text { Tutor apresenta cenário ao motorista: Perda de tempo; } \\
\text { perda de créditos. }\end{array}$ \\
Se combustível estiver em limiar inferior & $\begin{array}{l}\text { Tutor sugere parar o veiculo e abastecer } \\
\text { Se cometer infração }\end{array}$ \\
$\begin{array}{l}\text { (sinal fechado, atropelar pedestre, colisão); } \\
\text { Se chegar ao destino com o passageiro após } 30 \mathrm{~min} .\end{array}$ & $\begin{array}{l}\text { Tutor informa qual foi à perda em créditos de acordo com } \\
\text { tempo excedente }\end{array}$
\end{tabular}


Se chegar destino com o passageiro antes 30min Se houver obstáculo ou pedestre no caminho Se sinal fechado
Tutor informa qual foi o ganho em créditos.

Tutor sugere parar o táxi.

Tutor sugere parar o táxi e aguardar sinal verde

\section{RESULTADOS E CONCLUSÕES}

Ao modelar um agente tutor na arquitetura BDI, o "arquiteto" do sistema deve especificar apenas as crenças e desejos do agente, ficando a responsabilidade da escolha das intenções para o próprio agente através da análise dos estados iniciais disponíveis.

$\mathrm{O}$ tutor projetado com uma arquitetura de estados mentais torna-se mais robusto e ao mesmo tempo flexível. Adaptar o tutor para uma nova situação e contexto, significa excluir ou incluir novos estados mentais a cerca do ambiente, isto é, do caminho a ser percorrido, do tempo gasto e das regras que terão que ser respeitadas.

A arquitetura BDI tornou possível que o objetivo do projeto fosse alcançado, uma vez que possibilitou que o agente tutor orientasse o motorista de táxi na sua função de levar o passageiro a um destino pré-determinado, em um período inferior a 30 minutos.

Através deste trabalho percebeu-se que é possível e, seria de grande auxílio, tanto para os motoristas iniciantes bem como para os motoristas infratores, a ação de agentes tutores em veículos e auto-escolas. Supomos que o motorista utilizasse uma velocidade acima do permitido ou que estivesse dirigindo de modo a colocar em risco a sua vida ou de outrem, então o agente tutor faria sua interferência dando avisos sonoros, ou mensagens de alerta, ou até mesmo comunicando as irregularidades às autoridades competentes.

Para trabalhos futuros o sistema proposto pode ser estendido para ensinar um agente humano a dirigir um carro, isto é, ser um agente tutor para alunos de uma auto-escola. Isto poderá ser possível por intermédio de um estudo mais elaborado sobre as variáveis e a modelagem do sistema.

\section{REFERÊNCIAS BIBLIOGRÁFICAS}

BRATMAN, Michael E. Plans and Resource-Bounded Practical Reasoning. Dept. Philosophy. Stanford, California, 1988.

FLOREA, Adina Magda. Multi-agent Systems Lecture. University "Politehnica" of Bucarest. 2005. http://turing.cs.pub.ro/blia 2005. Acessado em 07/05/2006.

GIRAFFA,L.M.M. Uma arquitetura de tutor utilizando estados mentais. Porto Alegre:CPGCC-UFRGS, 1999. Tese de doutorado.

PEREIRA, A.S. Um Estudo de Aplicações de Ensino na Internet Orientada a Agentes. Porto Alegre: UFRGS, 1997.

WEISS, Gerhard. Multiagent systems: a modern approach to distributed artificial intelligence. MIT Press, 1999.

RUSSELL, S. J. e NORVIG, P. Artificial Intelligence, Prentice Hall, 1995. 